\title{
MODELLING E-HEALTH BUSINESS MODEL CANVAS BASED ON FINANCIAL FLOWS AND SHARED VALUE
}

\author{
Angela Martin ${ }^{1}$, Corentin Canu ${ }^{2}$, Camille Jean ${ }^{2}$, and Gabrièle Breda ${ }^{1}$ \\ ${ }^{1}$ ALTRAN Research Department, 2, rue Paul Dautier, 78457 Vélizy-Villacoublay, France \\ ${ }^{2}$ ENSAM, 151, bd de l'Hôpital, Paris, France
}

\begin{abstract}
The main focus of this study is to provide a new framework for business model design by using complex system modelling. The tool offers both entrepreneurs and investors a comprehensive view of value streams by comparing different business models based on the economic shared value creation during the go to market process.
\end{abstract}

\section{KEYWORDS}

Business Models, Innovation, Shared Value, Financial Flow Modelling, Deployment Model

\section{INTRODUCTION}

To survive in today's competitive economy, entrepreneurs need to find new markets to explore and new customer demand to capture. The mix between innovation and a good business model has proved to be effective. Yet, on the complex eHealth market, start-ups are facing major difficulties. Although many innovative projects are successfully tested, only a few lead to an economic return. Therefore, designing robust business models is a significant challenge for entrepreneurs.

The goal of this paper is to address this challenge by providing a framework for designing multiple business models and selecting the best ones based on economic shared value creation. Contrary to existing methods, our approach intends to tackle the complexity of business models by using complex system modelling methods. It aims to give both entrepreneurs and investors a comprehensive view of value streams. Finally, the comparison of business models guides investors and project leaders during the go to market process. 
The paper is organized as follows: in the next section, a literature review examines business model design and challenges. Then, the methodology is presented. The case study is detailed in the fourth section. Then, the deployment model of the case study is explained and the main results are discussed. Finally, a conclusion ends this paper.

\section{THEORETICAL BACKGROUND}

Business models and innovation are inter-linked. Innovation is the tool that creates value while the business model provides the explanation of how a company creates, delivers and captures value (Osterwalder and Pigneur, 2010). As a consequence, innovation triggers changes in all company activities, thus changing the business model itself. Just like the business model, it is essential to implement innovation (Chesbrough, 2002). Business models are vital for any start-up that intends to raise funds and are widely used especially in go to market strategies for innovations (Chanal, 2011).

A review of recent studies reveals a wide variety of business models. First, economists listed and described business models in use, like the franchise model or low cost model (Zott et al., 2011). Secondly, they defined the components (Krumeich et al., 2012). According to the literature review, business models are classified into four categories: value proposition, value network, value finance and value architecture (Al-Debei et al., 2008).

However, few business model design methods exist. Among the frameworks provided, the business model canvas introduced by Osterwalder and Pigneur (2010) is one of the first attempts to create a tool that specifically helps entrepreneurs to design business models. Based on creativity methods such as design thinking, business model canvas is effective especially in the early stage of projects or in a start-up environment.

The ModelH (Riley, 2016) is an adaptation of the business model canvas (see figure 1). It adds on Porter's theory of creating shared value (Porter and Kramer, 2011) and Christensen's jobs to be done (JTBD) (Christensen, 2013). Furthermore, it is specifically designed for the health sector. Indeed, health care business models must deal with the of stakeholders and their strong interdependency.

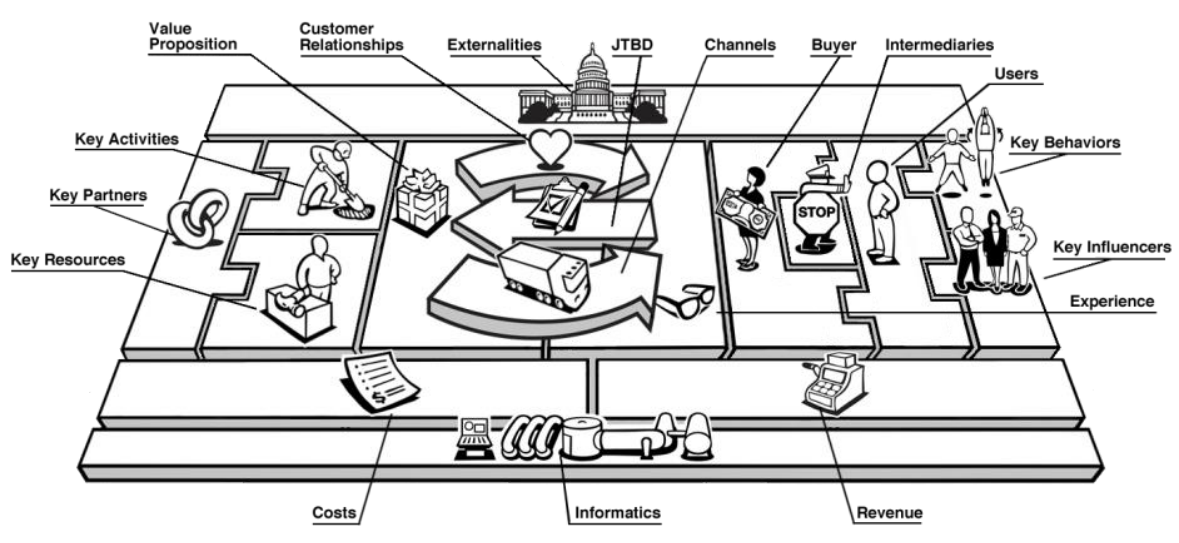

Source: modelH Business Model Canvas for Healthcare by Kevin Riley \& Associates. Drawings by Mike Werner

Figure 1. ModelH: Business Model Canvas for Healthcare 
In addition to business model canvas, Osterwalder and Pigneur (2010) proposed a business model design process that can be summed up as follows:

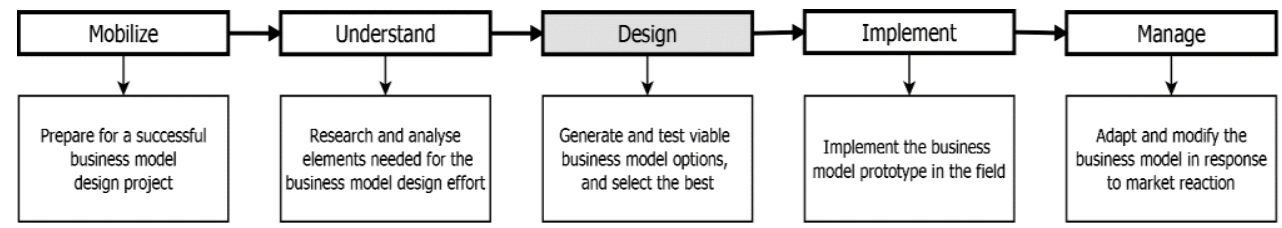

Figure 2. Business Model Design Process

During this process, the entrepreneur faces 5 major challenges:

1) Finding the right model

2) Testing the model before a full-scale launch

3) Inducing the market to adopt the new model

4) Continuously adapting the model in response to market feedback

5) Managing uncertainty.

Osterwalder and Pigneur (2010) offer entrepreneurs many tools to help design their business models and improve the innovation processes. Visual thinking, storytelling, and prototyping are some of them. Most of these methods are useful during early stages but there is still a lack of tools to test and select business models at the end of the design stage (identified as the third phase in figure 2).

Furthermore, the organization of the health industry is unique. Stakeholders are particularly dependent on each other and their multiplicity enhances the complexity of business models. Thus, the ecosystem of an innovative project / start-up can be seen as a complex system. We therefore look for complex system modelling tools useful for the implementation of an e-health business model.

\section{METHODOLOGY}

Jean's studies provide an example of the use of a complex system modelling method known as the financial flow modelling method (FFM) used to model the implementation of an innovative telehealth system (Jean et al., 2016). The FFM method identifies the added value of an innovative product/system. The main idea is to compare the existing scenario to the new one taking into account the new product/system. The key indicator of the FFM method is the annual margin balance i.e. the balance of profits and losses of each stakeholder when the new business system goes to market, as follows:

$$
\begin{gathered}
\text { Margin }_{M_{\text {before }}}=\text { Revenues }_{\text {before }}-\text { Cost }_{\text {before }} \\
\text { Margin }_{\text {after }}=\text { Revenues }_{\text {after }}-\text { Costs }_{\text {after }} \\
\text { Margin balance }=M_{\text {after }}-M_{\text {before }}
\end{gathered}
$$

The FFM method, illustrated in the next figure, was adapted in order to fit within the business model design process. In fact, the design phase offers a lot of inputs and the methodology must be as flexible as possible so that project leaders can adapt the business model according to the market response. The adapted FFM methodology is described in figure 3. 


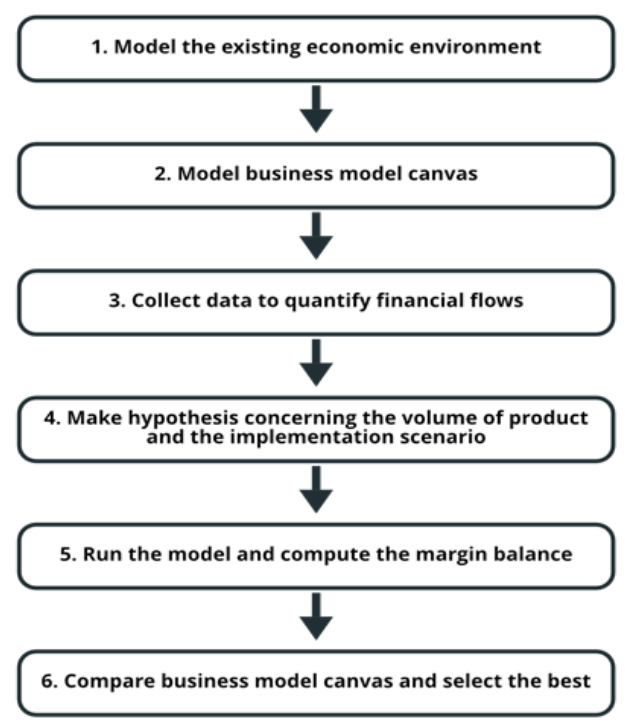

Figure 3. The methodology

The first step is to model the existing environment i.e. the economic environment where the innovation will be implemented. The second step is to model the business model canvas designed during the third phase of the business model design process (see figure 2). The third step is to collect data to quantify the financial flows inducted by the business models. Then, hypotheses must be made concerning the volume of product and the implementation scenario. The model is therefore run and the margin balance is computed. Finally, the business model canvases designed are compared based on the created shared value and the best one is selected. Hence, the use of FFM can help entrepreneurs or project leaders overcome three major challenges of the business model design process:

1. Finding the right model

2. Testing the model before a full-scale launch

3. Continuously adapting the model in response to market feedback.

\section{CASE STUDY: ECLAIRAGE}

The methodology presented above was tested on EclairAge, an innovative project conducted by the Research Department of Altran Group. EclairAge was selected and financed by the French Government as an eHealth demonstrator on the French territory. The project aimed to create and test innovative services that intend to improve elderly permanence of care in long-term dependency care centres (called EHPAD).

At present time, the continuity of care is provided by the French Emergency Services System (SAMU) that faces two major challenges. Firstly, SAMU affiliated physicians are not specialized in elderly care. Secondly, SAMU can quickly become congested. To face these challenges, the tele-expertise service EclairAge is a geriatric hot line for EHPAD's residents during weekdays. In case of an alarming situation, the nurse contacts EHPAD's coordinator 
IADIS International Journal on WWW/Internet

physician or the resident's attending physician. If the physician is available, the case is treated. If not, the nurse calls the emergency service or EclairAge.

Two main benefits arise from using the EclairAge geriatric hotline. First, based on the immediate transmission of EclairAge Emergency Files (containing the complete medical record of all EHPAD's residents), the on-call geriatrician is able to make personalized medical decisions to treat the case. As a consequence, transfers to the hospital or SAMU are avoided. In the case of a confirmed emergency, EclairAge can initiate the intervention of SOS Doctor (private emergency service). As a result, a physician is sent to the caller EHPAD. So, the case is treated without transferring the resident to the hospital. Second, when transfers are inevitable, the pre-diagnosis performed by EclairAge's geriatrician and the transmission of the resident's emergency file may shorten the waiting time at the hospital reception desk. In the case of a differed emergency, the on-call geriatrician can schedule a hospitalization and help find a hospital bed in geriatrics saving time and improving the residents' reassurance. EclairAge's workflow is schematized in figure 4.

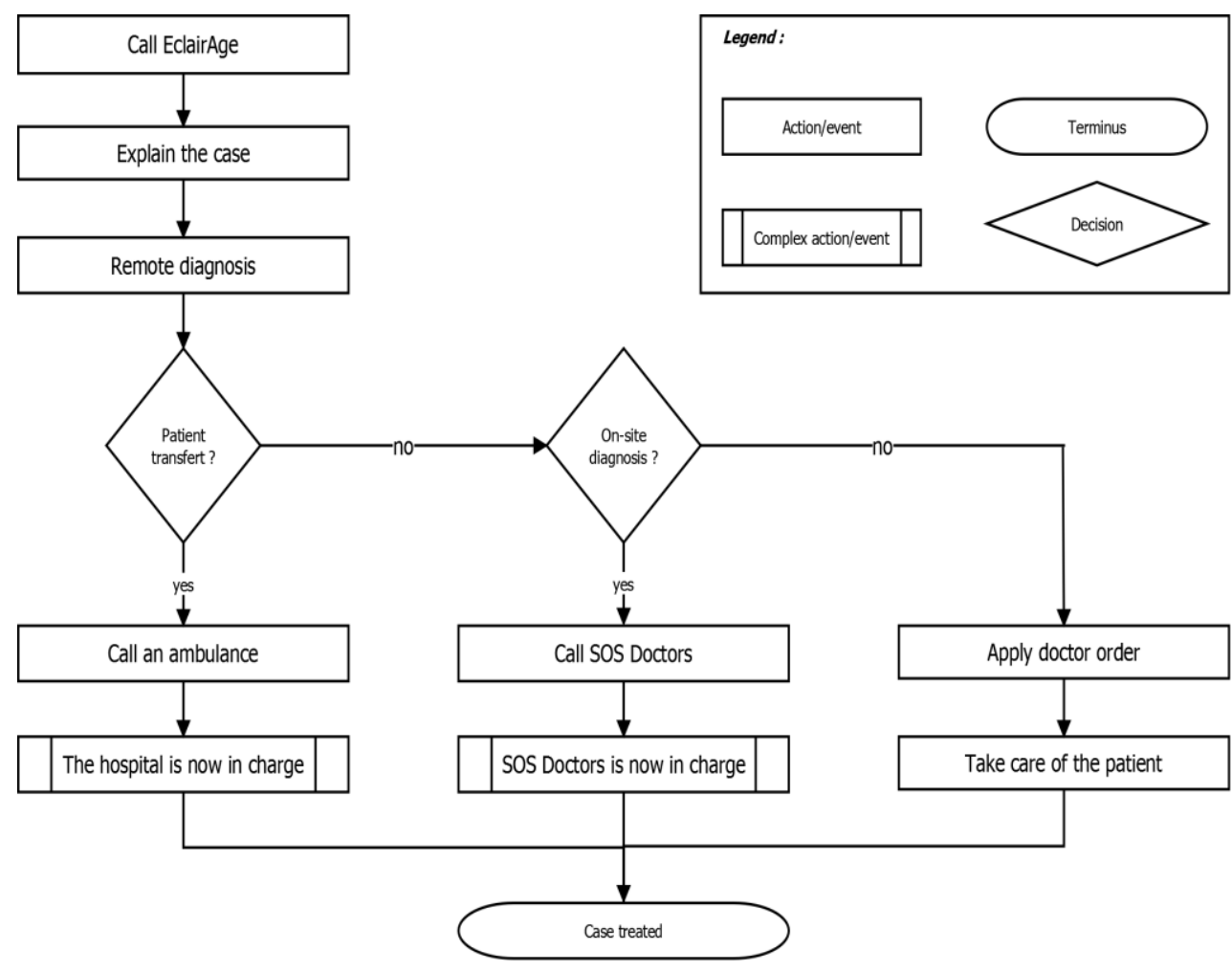

Figure 4. EclairAge Workflow

To assess the feasibility and viability of EclairAge, we conducted an in situ and in vivo non randomized trial in 5 French EHPADs situated in the South of the Essonne department (Ile de France region) for 18 months (August 2014- February 2016). An EclairAge geriatrician provided remote diagnosis during the experimental period. Emergency first aid and geriatric training were offered to EHPAD medical staff for the use of the EclairAge platform. The experiment data, useful for EclairAge deployment, is summed up in the following table. 
Table 1. EclairAge experiment data

\begin{tabular}{|l|l|}
\hline Data & Value \\
\hline Number of EHPADs & 5 \\
\hline Number of EclairAge calls & 51 \\
\hline Number of emergency transports & 11 \\
\hline Number of on-site interventions & 17 \\
\hline
\end{tabular}

\section{ECLAIRAGE DEPLOYMENT MODELLING}

The aim here is to provide a go-to-market strategy in order to implement EclairAge at regional level. Thus, the methodology presented in the third section is tested on EclairAge study case. Using FFM, we model the financial streams of each business model canvas and compare them to the financial streams of the current economic system. The goal is to choose the best business model based on the added value created by innovation before the go to market stage. FFM is adapted to fit within the business model design process so that project leaders can adapt the business model according to the market response.

\subsection{Model the Existing Economic Environment}

We start by modelling the current business model (Model 0). Before the implementation of EclairAge, no other system in place helped avoid the transferring of patients. In case of an alarming situation, if the EHPAD's coordinating physician and the patient's attending physician are not available, two options are available. Either the patient is transferred to the emergency service or a physician comes to the EHPAD (SOS Doctors). When patients are transferred, they usually go to the emergency department of the nearest hospital (GHT). EHPAD's residents are reimbursed by the National Health Insurance Fund (CNAM) and their private health insurance. We mapped the financial flows underlying the current permanence of elderly care in figure 5 with the associated equations in table 2 .

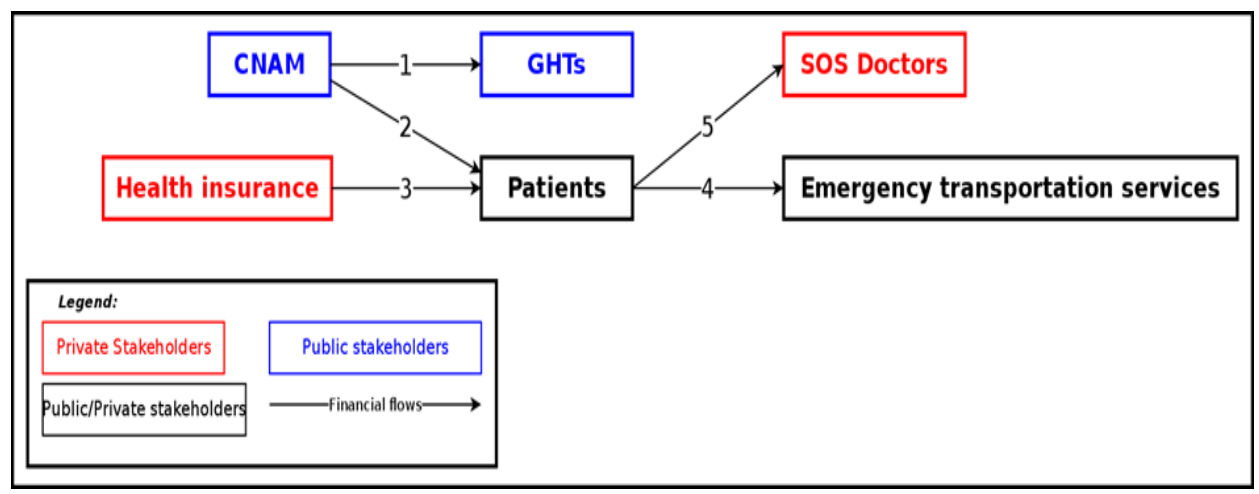

Figure 5. Financial Flows of the Current Business Model 
IADIS International Journal on WWW/Internet

Every arrow represents a parametrized flow.

For example: Flow 1 = Average Number of SAMU Calls per EHPAD * Hospitalizations Rate * Average Hospitalization Costs.

Table 2. Flow equations of the current financial flows

\begin{tabular}{|l|l|}
\hline Flow no. & Equation \\
\hline 1 & $P_{0} * P_{2} * P_{6}$ \\
\hline 2 & $P_{10} *\left(P_{0} * P_{4} * P_{8}+P_{0} * P_{3} * P_{7}\right)+P_{11} *\left(P_{1} * P_{5}+P_{0} * P_{5} * P_{9}\right)$ \\
\hline 3 & $P_{12} *\left(P_{0} * P_{4} * P_{8}+P_{0} * P_{3} * P_{7}\right)+P_{13} *\left(P_{1} * P_{5}+P_{0} * P_{5} * P_{9}\right)$ \\
\hline 4 & $P_{0} * P_{4} * P_{8}+P_{0} * P_{3} * P_{7}$ \\
\hline 5 & $P_{1} * P_{5}+P_{0} * P_{5} * P_{9}$ \\
\hline
\end{tabular}

Table 3 . The parameters of the equations

\begin{tabular}{|c|l|}
\hline Parameter no. & \multicolumn{1}{|c|}{ Parameter name } \\
\hline$P_{0}$ & Average Number of SAMU Call per EHPAD \\
\hline$P_{1}$ & Average Number of SOS Doctors Call per EHPAD \\
\hline$P_{2}$ & Average Hospitalization Cost \\
\hline$P_{3}$ & Average Simple Transportation Cost \\
\hline$P_{4}$ & Average Complicated Transportation Cost \\
\hline$P_{5}$ & Average On-site Intervention Cost \\
\hline$P_{6}$ & Hospitalizations Rate \\
\hline$P_{7}$ & Simple Transportation Rate \\
\hline$P_{8}$ & Complicated Transportation Rate \\
\hline$P_{9}$ & On-site Intervention Rate \\
\hline$P_{10}$ & Public Insurance Reimbursement Rate for Transportation \\
\hline$P_{11}$ & Public Insurance Reimbursement Rate for On-site Intervention \\
\hline$P_{12}$ & Private Insurance Reimbursement Rate for Transportation \\
\hline$P_{13}$ & Private Insurance Reimbursement Rate for On-site Intervention \\
\hline
\end{tabular}

\subsection{Model the New Business Model Canvas}

In order to build different scenarios for EclairAge business models, we conducted two workshops (brainstorming sessions) with different stakeholders of the local experimentation: the EclairAge Project Manager, the CEO of the software company that developed the EclairAge solution, a geriatrician, a physician from SOS Doctors, a SAMU representative, an economic expert and an eHealth specialist.

The ModelH (Riley, 2016) canvas is used to help synthetize the new organization. It comprises 17 key building blocks (see figure 1 for ModelH Canvas):

- Users are the customers that a business model serves. In this case, they refer to patients living in EHPAD. Indeed, EclairAge is a service that intends to improve permanence of care for the EHPAD's residents. 
- Buyers are the customers a business model sells to and may also be the Users. Here, buyers are National Health Institutions. They are the only ones that can allow the use of such a platform. Furthermore, in France, the permanence of care is financed by the government.

- Intermediaries affect how the Value Proposition is seen and paid for by the Buyers. The intermediaries are the EHPAD' medical staff and the geriatricians.

- JTBD Jobs-To-Be-Done are high-level goals the customer is trying to accomplish. The patients want to have the best care possible at any time.

- Value Proposition consists of products \& services offered to customers to solve their JTBD. The value proposition in this case is the EclairAge service.

- Channels describe how a company brings its Value Proposition to the market. The main channel, when it comes to selling e-health services to public health centres, is the Regional Health Agency (called ARS). ARS have the right to test and decide whether or not a product or service can be implemented in public health centres such as EHPADs.

- Customer Relationships are the connections that a company creates with their Buyers and Users. The local experiment was conducted with the help of the Age geriatric association $n$ that promoted the EclairAge service.

- $\quad$ Key Activities are the most important tasks required to create the Value Proposition. The key activity is to train geriatricians and medical staff on how to use the EclairAge platform. It is also important to monitor its use and make sure that the platform is running smoothly.

- Key Resources are the internal actors required to deliver the Value Proposition. To succeed in the key activities and deliver the value proposition, geriatricians, computer engineers and secretaries are as important as the data platform.

- Key Partners are the external players required to deliver the Value Proposition. There are two key partners in this case study. The first is the software company that developed the platform. The second is the geriatrics (Age) that delivers the training of EHPAD medical staff on how to use EclairAge.

- Costs are the most important financial driver of a business model. They are modelled in the next stage of our methodology. The key resources and the key activities are the main sources of cost.

- $\quad$ Revenue is the way a company gains money from its customers. This is modelled in the next stage of the methodology. We aim to generate revenue from the National Health Insurance Fund (CNAM) and private health insurances. In the current business model, their cost for each patient transfer is very high. They should therefore agree to pay for a system that will reduce the number of patient transfers.

- Informatics is the data and analytics needed to deliver and measure the Value Proposition. In our case, we will need a software and computer servers to support the EclairAge platform. It is important to monitor the use of the platform in order to adapt the business model accordingly.

- Externalities are the external forces \& regulations imposed upon a business model. These forces come mainly from the government. The EclairAge platform must be legal and follow the funding of permanence of care and health laws.

- Key Behaviours are the activities required of the Users to complete their JTBD.

- Key Influencers affect the User's understanding \& ability to complete their JTBD.

- Experience is how Buyers and Users perceive Channels and Customer Relationships. 
IADIS International Journal on WWW/Internet

The last three blocks do not generate financial flows. As a consequence, they are not taken into account in the business model. Still, they must be considered when building a complete business model according to Riley (2016).

The brainstorming sessions helped us design 3 business models for EclairAge: BM1, BM2, BM3. In BM1 and BM2, the hypothesis is that ARS invests in EclairAge in order to cover the implementation costs while the industrial sector invests in BM3. In BM1 and BM3, EclairAge pays Age, the geriatric association for each training session. A monthly fee is due to Age in BM2. The following table (table 4) sums up the differences between business models.

Table 4. EclairAge Business Models

\begin{tabular}{|l|l|l|}
\hline Business Models & Implementation stage stakeholder strategy & Training \\
\hline BM1 & ARS & Pay per training \\
\hline BM2 & ARS & Monthly payment \\
\hline BM3 & Industrial sector & Pay per training \\
\hline
\end{tabular}

Then, we mapped the financial flows underlying each business model with the new financial flows (figure 6).

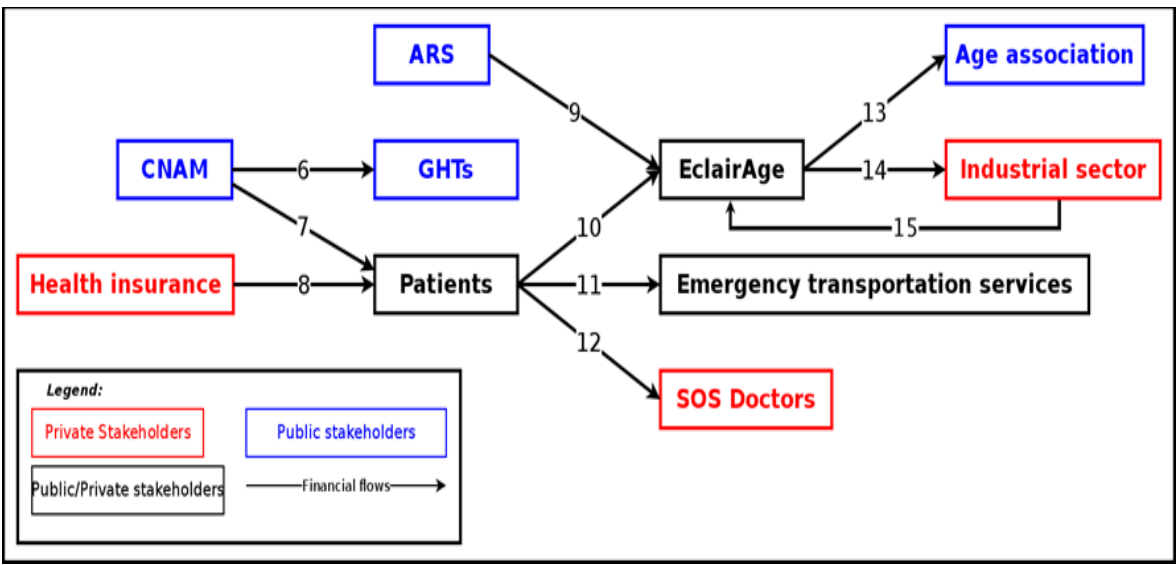

Figure 6. Financial Flows of the New Business Models

The main financial flows are summed up in the next table (table 5).

Table 5. Flow equations of the new financial flows

\begin{tabular}{|l|l|}
\hline Flow no. & Equations \\
\hline 6 & $\left(1-P_{14}\right) * P_{2} * P_{6}+P_{14} * P_{0} * P_{2} * P_{15}$ \\
\hline 7 & $\left(1-P_{14}\right) * F 2+P_{22} * P_{19} * P_{20} * P_{21}$ \\
\hline 8 & $\left(1-P_{14}\right) * F 3++P_{22} * P_{19} * P_{20} * P_{21}$ \\
\hline 9 & $P_{24}$ \\
\hline 9 & $P_{24}$ \\
\hline 10 & $P_{19} * P_{20} * P_{21}$ \\
\hline 11 & $P_{14} *\left(P_{0} * P_{4} * P_{17}+P_{0} * P_{3} * P_{16}\right)+\left(1-P_{14}\right) *\left(P_{0} * P_{4} * P_{8}+P_{0} * P_{3} * P_{7}\right)$ \\
\hline 12 & $P_{1} * P_{5}+P_{14} * P_{0} * P_{5} * P_{18}+\left(1-P_{14}\right) *\left(P_{1} * P_{5}+P_{0} * P_{5} * P_{9}\right)$ \\
\hline 13 & $P_{28} * P_{29}+P_{32} * P_{31}$ \\
\hline 13 & $P_{28} * P_{29}+P_{34} * P_{33}$ \\
\hline 14 & $P_{27} * P_{25}+P_{26} * P_{30}+P_{35}$ \\
\hline
\end{tabular}


The following table (table 6) shows the equations that must be taken into account for each business model.

Table 6. Equations of the new business models

\begin{tabular}{|l|l|}
\hline Business Models & Equations \\
\hline BM1 & $1,2,3,4,5,6,7,8,9,10,11,12,13,14$ \\
\hline BM2 & $1,2,3,4,5,6,7,8,9,10,11,12,13^{\prime}, 14$ \\
\hline BM3 & $1,2,3,4,5,6,7,8,9,9^{\prime}, 10,11,12,13,14$ \\
\hline
\end{tabular}

The parameters that drive the economic model are presented in table 7.

Table 7. Parameters of the new business models

\begin{tabular}{|c|c|c|}
\hline Parameter & Description & Value \\
\hline$P_{0}$ & $\begin{array}{l}\text { Average Number of SAMU Calls per EHPAD per } \\
\text { month }\end{array}$ & 1.6875 \\
\hline$P_{1}$ & $\begin{array}{l}\text { Average Number of SOS Doctor Calls per EHPAD per } \\
\text { month }\end{array}$ & 0.175 \\
\hline$P_{2}$ & Average Hospitalization Cost & 161.5 \\
\hline$P_{3}$ & Average Simple Transportation Cost & 186 \\
\hline$P_{4}$ & Average Complicated Transportation Cost & 1186 \\
\hline$P_{5}$ & Average On-site Intervention Cost & 50 \\
\hline$P_{6}$ & Hospitalizations Rate & 0.8794 \\
\hline$P_{7}$ & Simple Transportation Rate & 0.7338 \\
\hline$P_{8}$ & Complicated Transportation Rate & 0.1456 \\
\hline$P_{9}$ & On-site Intervention Rate & 0 \\
\hline$P_{10}$ & $\begin{array}{l}\text { Public Insurance Reimbursement Rate for } \\
\text { Transportation }\end{array}$ & 0.65 \\
\hline$P_{11}$ & $\begin{array}{l}\text { Public Insurance Reimbursement Rate for On-site } \\
\text { Intervention }\end{array}$ & 0.7 \\
\hline$P_{12}$ & $\begin{array}{l}\text { Private Insurance Reimbursement Rate for } \\
\text { Transportation }\end{array}$ & 0.35 \\
\hline$P_{13}$ & $\begin{array}{l}\text { Private Insurance Reimbursement Rate for On-site } \\
\text { Intervention }\end{array}$ & 0.3 \\
\hline$P_{14}$ & EclairAge Call Rate & 0.5 \\
\hline$P_{15}$ & EclairAge Hospitalizations Rate & 0.215 \\
\hline$P_{16}$ & EclairAge Simple Transportation Rate & 0.215 \\
\hline$P_{17}$ & EclairAge Complicated Transportation Rate & 0 \\
\hline$P_{18}$ & EclairAge On-site Intervention Rate & 0.3333 \\
\hline$P_{19}$ & EclairAge Subscription Price per Patient & 3.5 \\
\hline$P_{20}$ & No of patients per EHPAD & 72 \\
\hline$P_{21}$ & No of EHPAD connected to the EclairAge Platform & From 0 to 100 \\
\hline$P_{22}$ & $\begin{array}{l}\text { Public Insurance Reimbursement Rate for EclairAge } \\
\text { Subscription }\end{array}$ & 70 \\
\hline$P_{23}$ & $\begin{array}{l}\text { Private Insurance Reimbursement Rate for EclairAge } \\
\text { Subscription }\end{array}$ & 30 \\
\hline$P_{24}$ & Investment per month & 10000 \\
\hline$P_{25}$ & Software Maintenance Cost & 100 \\
\hline
\end{tabular}




\begin{tabular}{|l|l|l|}
\hline$P_{26}$ & Software Installation Cost & 1000 \\
\hline$P_{27}$ & No of computers & From 0 to 100 \\
\hline$P_{28}$ & No of employees & From 0 to 3 \\
\hline$P_{29}$ & Monthly salary of an employee & 4000 \\
\hline$P_{30}$ & No of new computers per month & At least 4 \\
\hline$P_{31}$ & No of medical staff per EHPAD that must be trained & 5 \\
\hline$P_{32}$ & Unitary Training Cost & 200 \\
\hline$P_{33}$ & No of trainers hired & 1.5 \\
\hline$P_{34}$ & Monthly salary of a trainer & 4000 \\
\hline$P_{35}$ & Data Hosting Cost per Month & 300 \\
\hline
\end{tabular}

\subsection{Collect Data to Quantify Financial Flows}

The third stage of FFM is to collect data to quantify the parameters. Anonymized data was collected from: EHPAD's annual reports, SAMU of Essonne data base, SOS Doctors data and excel sheets and the EclairAge dashboard of geriatric calls. We also conducted semi-structured interviews with relevant stakeholders to get an estimation of the parameter (integrating confidence intervals) when quantitative data was not available.

The local experiment data conducted in 5 EHPADs provided some crucial information. There are 51 calls using the EclairAge platform. $38 \%$ of them have resulted in emergency transports and thus in hospitalizations. The limited number of calls must be taken into account. As a consequence, we must define confidence intervals.

According to the following formula, we can deduce $95 \%$ intervals confidence from the local experiment results:

Where:

$$
p\left(\frac{S_{i}}{N}-1,96 \sqrt{\frac{\left(\frac{S_{i}}{N}\right) *\left(1-\frac{S_{i}}{N}\right)}{N}}<p<\frac{S_{i}}{N}+1,96 \sqrt{\left.\frac{\left(\frac{S_{i}}{N}\right) *\left(1-\frac{S_{i}}{N}\right)}{N}\right) \approx 0,95}\right.
$$

$N=51$, number of EHPADs

$S_{1}=11$, number of emergency transports

$S_{2}=17$, number of on - site interventions

For $S_{1}$, the $95 \%$ confidence interval is: $[0,10 ; 0,32]$.

For $S_{2}$, the $95 \%$ confidence interval is: $[0,20 ; 0,46]$.

When modelling the impact of EclairAge on the permanence of care, we consider that between $10 \%$ and $32 \%$ of EclairAge calls result in emergency transports and between $20 \%$ and $46 \%$ of calls result in on-site interventions.

\subsection{Make Hypothesis Concerning the Volume of Product and the Implementation Scenario}

The next stage of our methodology concerns the hypotheses about the volume of product and the implementation scenario. The deployment scenarios are issued from the interviews with the stakeholders involved in the project. As the local experiment was conducted in the French Essonne department, the goal was to implement the EclairAge platform in the 100 EHPADs located in the Essonne department starting from September 2016. One EHPAD would be connected to the platform each week except during July and August due to the French holiday 
period. It takes up to 3 months to train the medical staff to use the informatics platform in each EHPAD. In fact, service innovations are the most difficult to implement because of the resistance to change. As a consequence, during the first 3 months, EHPAD's medical staff would not use the EclairAge platform so the current business model would continue to be used.

As a consequence, we assume it will take more than 2 years to locally implement the service. Therefore, our model runs on a 6 years' period so that we can observe how it works, both during and after the implementation.

The assumptions for the implementation scenario are summed up in the next table (table 8).

Table 8. Implementation scenario hypothesis

\begin{tabular}{|l|l|l|l|}
\hline Parameter & Value & Unit & Source \\
\hline Total Number of EHPAD & 100 & EHPAD & (KPMG, 2014) \\
\hline No of EHPADs connected to the platform per month & 4 & EHPAD & Interviews \\
\hline Time delay between connection and use of the platform & 3 & Month & Interviews \\
\hline
\end{tabular}

\subsection{Compute the Model and Calculate the Margin Balance}

All modelled scenarios are now simulated so we can compare the margin balance of each stakeholder present in the financial flows. The following graphs $(6,7$, and 8$)$ show the sum of margin balances over time.

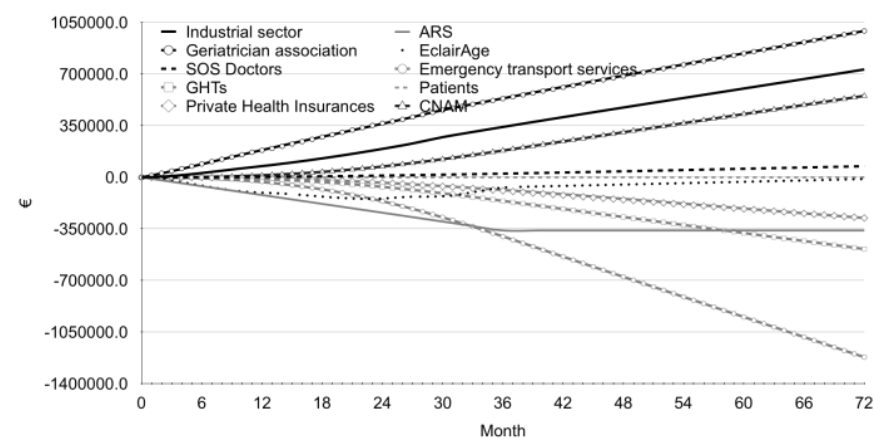

Figure 6. Total margin balances for BM1

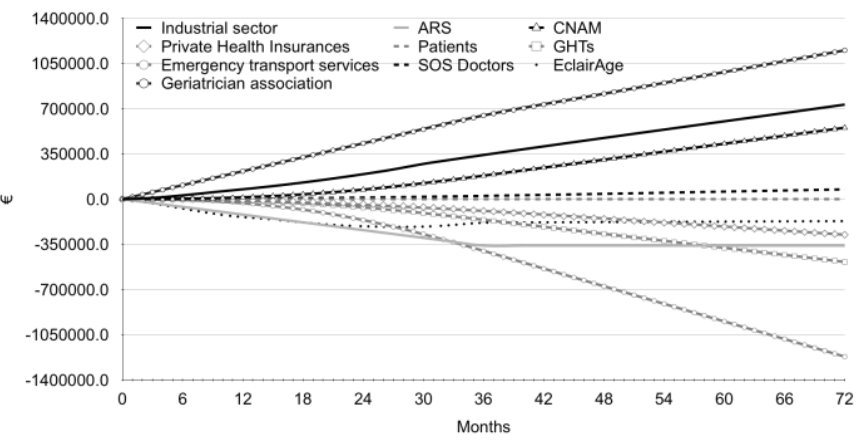

Figure 7. Total margin Balances for BM2 
IADIS International Journal on WWW/Internet

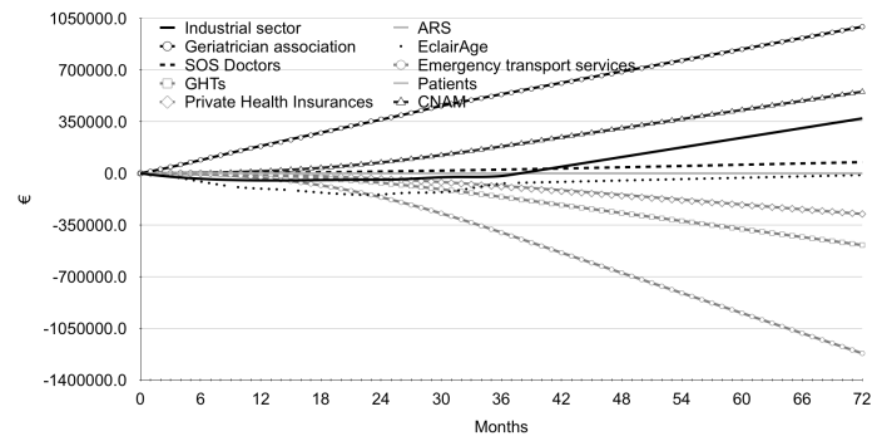

Figure 8. Total margin balances for BM 3

The figures show that there is little difference between the three business models (BM1, BM2, and BM3). The shared value is the same for the following stakeholders: SOS Doctors, GHTs, Patients, CNAM, Emergency Transport Services, and Private Health Insurance. In all cases, CNAM, SOS Doctors and the geriatric association Age have a positive margin balance if EclairAge is implemented. However, emergency transport services, private health insurances, GHTs are losing money in the process. The business models are designed so that patients don't spend any money, so their margin balances are null over time. Some differences are to be noted for the following stakeholders: Industrial sector, ARS, Age association, and EclairAge.

\subsection{Compare Business Models and Select the Best}

The comparison of BM scenarios can provide some inputs for decision makers. Here, we focus on attracting new investors and managing key resources and activities.

Looking at the first scenario, modelling shared value created by innovation is a good way to attract investors. In fact, figure 9 shows that the industrial sector - especially software companies - has a certain interest in the deployment of EclairAge.

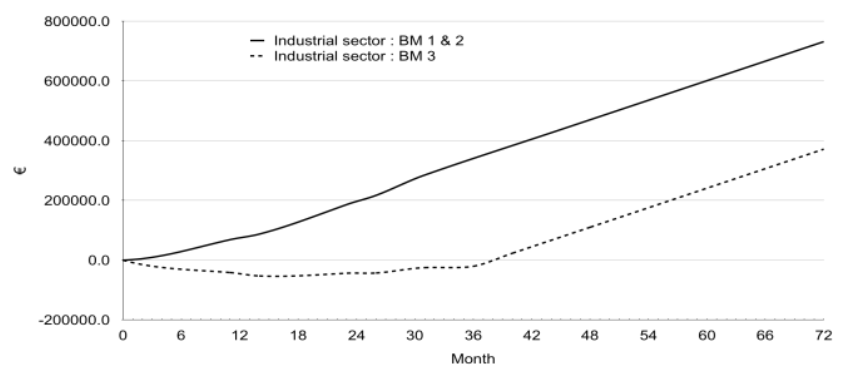

Figure 9. Total Margin Balances of the Industrial Sector

In fact, in the current business model of care permanence, they are not at all involved Whatever new business model they choose to implement, they will make profit. In the first two business models, they earn money as soon as the service is implemented in an EHPAD while in the last scenario they must wait about 3 years to have a return on their investment.

The French health system is not used to private investments. However, private investments can be extremely useful when deploying innovative services or products on the e-health market 
at a lower cost for the government as well as improving the quality of care services in the same time.

When managing key resources and activities, our tool can also be useful to compare training costs (see figure 10). As a result, on the one hand, it is more relevant to pay a monthly salary for EHPADs' training sessions during the first 3 years of the EclairAge implementation. On the other hand, once EclairAge is fully implemented, it is more relevant to pay per training session. As a consequence, our tool provides inputs for cost forecasts thus adjusting the key resources and activities.

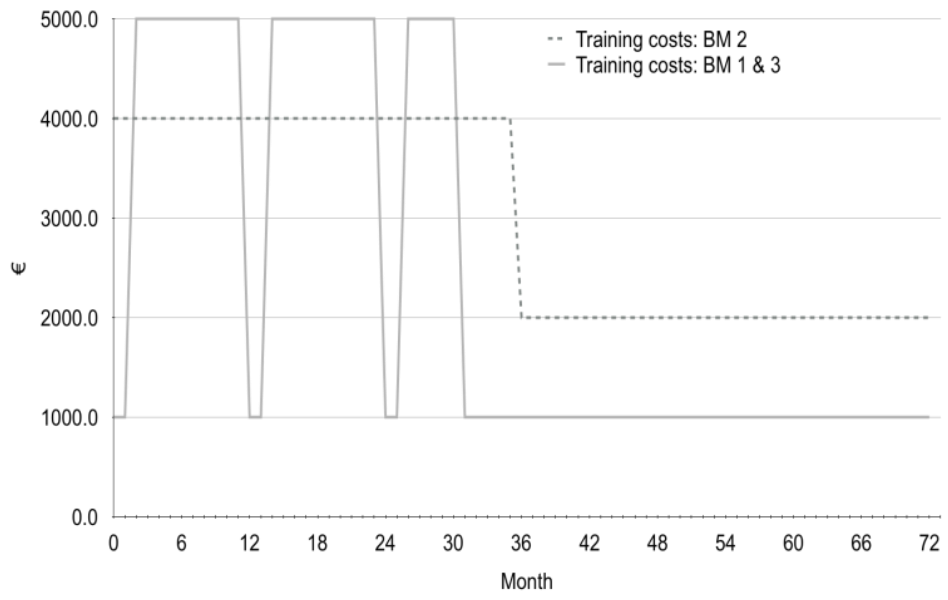

Figure 10. Training Costs

\section{CONCLUSION}

Our framework, combining Financial Flow Modelling (FFM) and Business Model Canvas (BMC), provides 5 main benefits.

1) The framework reinforces the consistency of business models. Through scenarios simulation, the cost and revenue structure are in line with the resources and activities.

2) A systemic approach is useful to design business models for early stage innovative projects when entrepreneurs must react quickly. The FFM method allows entrepreneurs to test a wide variety of business models and to choose the best one in accordance with the implementation scenario and market response.

3) The business model developed for the case study is both flexible and complete. Thus, we are able to model 3 coherent business models and select the most appropriate for the implementation of EclairAge tele-expertise service.

4) The results of empirical studies show that detailed business models are more pertinent for investors (Chanal, 2011). The detailed financial structure quantifying long and short term benefits can help convince some stakeholders to invest in innovative projects.

5) BMC together with FFM can be widely used for key business activities including: resource allocation, short and long-term planning, decision-making support, business strategy, and profit optimization. 
IADIS International Journal on WWW/Internet

This tool helps entrepreneurs compare and select the best business model canvas based on financial shared value. Further work is needed to implement a selection tool based on social value created. In fact, according to Porter (2011), generating social and medical value is an advantage for companies. Furthermore, the development and use of a second tool provides a multi-perspective approach that enhances both the quality and the validity period of the business model (Fendt, 2002), clearly indicating advantages, limitations and possible applications.

\section{REFERENCES}

Al-debei, M., El-Haddadeh, R. and Avison, D. 2008. Defining the Business Model in the New World of Digital Business, In Proceedings of the Americas Conference on Information Systems (AMCIS), pp. 1-11.

Chanal V., 2011. Business Models dans l'innovation: pratiques et méthodes. Presses Universitaires de Grenoble.

Chesbrough, H., 2007. Business model innovation: it's not just about technology anymore, In Strategy \& Leadership, Vol. 35, no. 6, pp.12-17.

Chesbrough, H., and. Rosenbloom, R. 2002. The role of the business model in capturing value from innovation: evidence from Xerox Corporation's technology spin-off companies, In Ind. Corp. Chang., vol. 11, no. 3, pp. 529-555.

Christensen, C. and Raynor. M., 2013. The innovator's solution: Creating and sustaining successful growth. Harvard Business Review Press.

Fendt C., 2002. Meaning, legitimacy and impact of business models in fast moving environments, University of East London.

Jean, C., Duong, T., Cardinal, J., Jankovic, M., Bocquet J., and Espinoza P., 2016. Sharing economic value between the stakeholders of a telehealth project: methodological issues? In Eur. Res. Telemed., vol. 5, pp. 37-44, 2016.

Klein, K., and Knight, A., 2005. Innovation Implementation: Overcoming the Challenge, In Current Directions in Psychological Science, Vol. 14, No. 5, pp. 243-246.

KPMG, Observatoire des EHPAD, 2014.

Krumeich, J., Burkhart T., Werth D., and Loos, P., 2012. Towards a Component-based Description of Business Models- A State-of-the-Art Analysis, In AMCIS 2012 Proc., p. 19, 2012.

Lee, J., Shin, D., Hong, Y., and Kim, Y., 2011. A Structured Approach to Business Modeling for Strategic Planning of Innovative Product-Service System, In The 41st International Conference on Computers \& Industrial Engineering (C\&IE), Los Angeles, CA.

Lewandowski, M., 2016. Designing the Business Models for Circular Economy- Towards the Conceptual Framework, In Sustainability, Vol. 8, No. 1, p. 43.

Porter, M., and Kramer, M., 2011. Creating shared value - How to reinvent capitalism and unleash a wave of innovation and growth, In Harvard Business Revue, vol. 39, pp. 62-77.

Riley K., Our model, 2016. [Online]. Available: http://imaginego.com/modelh/.

Osterwalder, A. and Pigneur, Y., 2010. Business Model Generation. John Wiley \& Sons.

Zott, C., Amit, R. and Massa, L., 2011. The Business Model: Recent Developments and Future Research, In J. Manage., vol. 37, no. 4, pp. 1019-1042. 